\title{
Lack of Association of Chronic Liver Disease in Patients with Oral Lichen Lanus
}

\author{
Ganesh Shreekanth Nellithady ${ }^{1 *}$, Koneru Anila ${ }^{2}$, Kattappagari Kiran Kumar ${ }^{1}$ and Hallikeri Kaveri ${ }^{1}$ \\ ${ }^{1}$ Oral and Maxillofacial Pathology, SDM college of dental sciences and hospital, dharwad, karnataka, India \\ ${ }^{2} S D M$ College of dental sciences and hospital, dharwad, karnataka, India
}

\begin{abstract}
Background: Lichen Planus is a chronic inflammatory disease of oral mucosa and skin. In recent years, several reports have emphasized a possible relationship between lichen planus and liver disease. Serum glutamic oxaloacetic transaminases (SGOT), serum glutamic pyruvic transaminase (SGPT) are the most useful measures for liver cell injury.
\end{abstract}

Purpose: To compare the levels of SGOT and SGPT in oral lichen planus patients and healthy controls to observe the existence of liver disease.

Materials and Methods: The sample comprised 30 oral lichen planus patients and 30 healthy controls. The blood samples were collected from both the groups and subjected to biochemical analysis for SGPT and SGOT enzymes using semi automated biochemistry analyser. Statistical analysis was done using unpaired t-test $(p<0.05)$.

Results: Mean distribution of SGOT and SGPT in oral lichen planus are 23.18, 25.18 whereas in control group are $20.07,17.53$ respectively. SGOT levels showed a statistical significant difference between oral lichen planus patients and control group but not the SGPT levels.

Conclusion: Our study showed no significant correlation between oral lichen planus and presence of liver disease. Although an increased level of SGOT enzymes in the absence of elevated SGPT levels were observed but this does not signify liver disease.

Keywords: India; Liver disease; Oral lichen planus; Serum Glutamic Oxaloacetic Transaminase (SGOT); Serum Glutamic Pyruvic Transaminase (SGPT)

\section{Introduction}

Lichen planus (LP) is relatively common, chronic inflammatory mucocutaneous disease of the oral mucosa and skin, which was first described by Wilson. Oral lichen planus (OLP) affects $0.1-4 \%$ of the world's population and $1.5 \%$ of Indian population [1]. Although LP is pan racial, the incidence appears greater in whites than in blacks, Orientals, or American Indians [2]. It is a disease of middle age but occasionally can be seen in children [3].

Oral manifestations are characterized by raised multiform white lesions accompanied by areas of erosion and pigmentation [1]. OLP shows different clinical patterns than those of cutaneous counterpart, and are categorized as reticular, papular, plaque-like, atrophic, erosive, and bullous forms. Malignant transformation of OLP, especially the erosive variety, showing $0.5-2.5 \%$ of transformation, but the pre-malignant potential of lichen planus is still controversial [3].

The etiopathogenesis appear to be complex with interaction of genetic, environmental, and lifestyle factors, although the exact mechanisms involved are not much. However an interesting new association of LP with liver disease has been emerged Scully et al. [3].

In recent years, several studies have emphasized a possible relationship between lichen planus and chronic liver disease, particularly primary biliary cirrhosis and chronic active hepatitis. The prevalence of this association varies widely in the literature. Erosive oral lichen planus is particularly stated to show an association with chronic liver disease in Southern Europe but the studies done on Scandinavian and British OLP patients have failed to show any significant association Carrozo [4].

Serum aminotransferase enzyme levels such as Serum glutamic oxaloacetic transaminase (SGOT) and serum glutamic pyruvic transaminase (SGPT) are the most useful measures for liver cell injury. They are considered as sensitive indicators of liver damage or injury from different types of disease [5].

Elevated SGOT level may also be seen in acute muscle injury particularly in cardiac or skeletal muscle. Diseases that primarily affect hepatocytes, such as viral hepatitis, will cause disproportionate elevation of the SGOT and SGPT levels when compared to alkaline phosphatase levels. In viral hepatitis and other forms of disease associated with hepatic necrosis, blood levels of SGOT and SGPT are elevated even before clinical signs and symptoms of disease appear. The SGOT and SGPT levels show a variable increase during the prodromal phase of acute viral hepatitis and precede the rise in bilirubin level. Specific antigens and antibodies establish the diagnosis of viral hepatitis [6].

SGOT levels are considered to be less specific for liver disease when comparing to SGPT levels. It must be emphasized that higher than normal levels of these liver enzymes should not be automatically equated to liver disease. Elevated SGOT and SGPT may or may not involve with liver problems. The interpretation of elevated SGOT and SGPT levels depends upon the entire clinical evaluation of a patient [5].

*Corresponding author: Ganesh Shreekanth Nellithady, Assistant Professor MDS in Oral and Maxillofacial Pathology, SDM College of dental sciences and hospital, dharwad, karnataka, India, Tel: +91-98-4461 6581; Fax: 0836-2467612; E-mail: shreekanthng@gmail.com

Received November 28, 2010; Accepted December 28, 2010; Published December 29, 2010

Citation: Nellithady GS, Anila K, Kumar KK, Kaveri H (2010) Lack of Association of Chronic Liver Disease in Patients with Oral Lichen Lanus. J Carcinogene Mutagene 1:113. doi:10.4172/2157-2518.1000113

Copyright: () 2010 Nellithady GS, et al. This is an open-access article distributed under the terms of the Creative Commons Attribution License, which permits unrestricted use, distribution, and reproduction in any medium, provided the original author and source are credited. 
Hence the aim of the present study is to compare the levels of SGOT and SGPT as an indicator of liver disease using blood samples of oral lichen planus patients and healthy controls and to observe the presence of liver disease associated with oral lichen planus patients residing in Dharwad district population in India.

\section{Materials and Methods}

\section{Patients}

A total of 30 ( 15 males \& 15 females) histopathologically proven oral lichen planus patients were taken as a study group and 30 age and sex matched healthy individuals were taken as control group. 3 clinical types of OLP patients were taken i.e. reticular LP, erosive LP and bullous LP. Patients with any habit, medication and systemic illness were excluded. Informed consent was obtained from all the patients prior to the study. Ethical clearance was obtained from ethical committee of SDM College of dental sciences and Rajiv Gandhi University of health sciences, Bangalore, India.

\section{Collection of samples}

Blood samples were obtained from both the groups. $5 \mathrm{ml}$ was collected by venous arm puncture under aseptic precautions and transferred into a presterilized plain vials. These collected blood samples were then centrifuged at $3000 \mathrm{rpm}$ for $10 \mathrm{mins}$ to separate the serum and erythrocytes. Serum samples were then used for SGOT and SGPT analysis using semiautomatic biochemistry analyser (Erba Chem 5- plus V2 marketed by transassia biomedicals. Ltd).

\section{Biochemical measurement}

Estimation of SGOT and SGPT was performed by taking $1000 \mu \mathrm{l}$ of working reagent (ERBA SGOT \& SGPT kit) into a test tube containing $100 \mu \mathrm{l}$ of serum. Solution is mixed thoroughly and incubated at $37^{\circ} \mathrm{C}$ for 1 minute. Later the solution is processed by placing the test tube in semiautomatic biochemistry analyzer.

One international unit (IU) of SGOT and SGPT (IU/L) is defined as the amount of enzyme that catalyzes the transformation of one

\begin{tabular}{|l|l|l|l|}
\hline Age in years & Lichen Planus patients & Control Group & Total \\
\hline $20-39$ & $14(46.67 \%)$ & $14(46.67 \%)$ & 28 \\
\hline $40-59$ & $12(40.00 \%)$ & $12(40.00 \%)$ & 24 \\
\hline$>60$ & $4(13.33 \%)$ & $4(13.33 \%)$ & 8 \\
\hline Total & $30(100 \%)$ & $30(100 \%)$ & 60 \\
\hline
\end{tabular}

Table 1: Age Distribution in Lichen planus and control group.

\begin{tabular}{|l|l|l|l|}
\hline Clinical type of LP & Male & Female & Total \\
\hline Reticular LP & $6(40 \%)$ & $7(46.66 \%)$ & $13(43.33 \%)$ \\
\hline Erosive LP & $9(60 \%)$ & $6(40 \%)$ & $15(50 \%)$ \\
\hline Bullous LP & $0(0 \%)$ & $2(13.33 \%)$ & $2(6.66 \%)$ \\
\hline Total & $15(100 \%)$ & $15(100 \%)$ & $30(100 \%)$ \\
\hline
\end{tabular}

Table 2: Sex Distribution in clinical types of LP group.

\begin{tabular}{|l|l|l|l|l|l|}
\hline Enzymes & Reticular LP & Erosive LP & Bullous LP & p-value & Significance \\
\hline SGPT & $19.84+7.1$ & $26.10+8.6$ & $23.00+7.07$ & 0.13 & NS \\
\hline SGOT & $22.96+9.2$ & $25.42+11.7$ & $37.80+28.5$ & 0.27 & NS \\
\hline
\end{tabular}

Table 3: Comparison of mean SGPT and SGOT among clinical subtypes of LP.

\begin{tabular}{|l|l|l|l|l|l|}
\hline Group & No of sample $(\mathbf{n})$ & Mean + SD & t- value & p-value & Significance \\
\hline LP & 30 & $25.18+11.98$ & \multirow{2}{*}{3.43} & 0.001 & S \\
\hline Control & 30 & $16.95+5.30$ & & & \\
\hline
\end{tabular}

Table 4: Comparison of SGOT levels between LP groups and control groups. micromole of substrate per minute under specified conditions. The mean absorbance change per minute $(\triangle \mathrm{Abs} / \mathrm{min})$ for every reading is noted. The mean values of SGOT and SGPT levels were calculated.

\section{Statistical analysis}

The findings are expressed as Mean \pm S.D. Statistical analysis was performed using unpaired t-test. P value $<0.05$ was considered statistically significant.

\section{Results}

The maximum number of cases were in the age group of 20-39 years [14 OLP cases (46.67\%) and 14 control group (46.67\%)]. Age distribution in both OLP and control group are shown in Table 1. The mean age in study and control group was $41.70 \pm 13.34$. 50\% were males and $50 \%$ females in both study and control groups.

In 30 cases of OLP patients, 13 cases showed reticular LP, 15 erosive LP and only 2 were bullous LP. Maximum number of male patients had erosive LP (9cases, 60\%) where as maximum number of female patients had reticular LP (7 cases, 46.6\%) and 2 cases of bullous LP were seen in female patients which is shown in Table 2.

The Mean SGPT levels in different clinical types i.e. reticular LP, erosive LP and bullous LP are $19.84+7.19,26.10+8.63,23.00+$ 7.07 respectively, whereas mean SGOT levels in different clinical types are $22.96+9.28,25.42+11.75,37.80+28.56$ respectively. However there is no statistically significant difference for mean SGPT and SGOT levels between different clinical types of OLP patients (Table 3).

The Mean distribution of SGOT levels in OLP patients and control group were $25.18 \pm 11.98$ and $16.95 \pm 5.30$ respectively. There is a statistically significant difference for mean SGOT levels between the study and control group at 5\% level of significance ( $P$ - 0.001) (Table 4).

The Mean distribution of SGPT levels in OLP patients and control group were $23.18 \pm 8.28$ and $19.87 \pm 6.44$ respectively. There was no statistically significant difference for mean SGPT levels between study and control group at 5\% level of significance (P- 0.05) (Table 5).

The mean SGOT levels were higher than SGPT levels in oral lichen planus whereas SGPT levels were higher than SGOT levels in control group shown in Table 6.

\section{Discussion}

Lichen planus is a relatively common chronic mucocutaneous disorder that may affect skin, oral mucosa or both. Although it can be seen in any site, but predominantly it is manifested in the buccal and labial mucosa in the oral cavity [7].

OLP is thought to be seen in association with a number of systemic diseases like liver disorders, hypertension and diabetes mellitus [8]. However most of the affected patients are seen in middle and late life, thus they are liable to many systemic diseases [9].

The etiology of LP is controversial, although many authors have investigated and supported an immunological pathogenesis [7]. Recent studies showed LP is a T cell mediated autoimmune disease in which cytotoxic CD8 $+\mathrm{T}$ cells trigger the apoptosis of oral epithelial cells. The CD8 $+\mathrm{T}$ cells in the lesion may recognize an antigen associated with the MHC class 1 on keratinocytes. After antigen recognition and activation, $\mathrm{CD} 8+$ cytotoxic $\mathrm{T}$ cells may trigger keratinocyte apoptosis. Activated CD8 $+\mathrm{T}$ cells may release cytokines that attracts additional lymphocytes into the lesion [1]. 


\begin{tabular}{|l|l|l|l|l|l|}
\hline Group & No of sample (n) & Mean + SD & t- value & p-value & Significance \\
\hline LP & 30 & $23.18+8.28$ & \multirow{2}{*}{1.77} & 0.08 & NS \\
\hline Control & 30 & $19.87+6.44$ & & & \\
\hline
\end{tabular}

Table 5: Comparison of SGPT levels between LP groups and control groups.

\begin{tabular}{|l|l|l|l|l|}
\hline \multirow{2}{*}{} & \multicolumn{2}{|l|}{ LP(Group I ) } & \multicolumn{2}{l|}{ Control(Group II) } \\
\cline { 2 - 5 } & SGPT & SGOT & SGPT & SGOT \\
\hline Mean \pm SD & $23.18+8.28$ & $25.18+11.98$ & $20.07+6.43$ & $17.53+6.14$ \\
\hline Median & 21.00 & 21.00 & 19.00 & 17.00 \\
\hline
\end{tabular}

Table 6: Mean distribution of SGPT and SGOT in LP and control group.

Thus Lymphocytes, particularly T- cells, play an important role in LP. Other factors include antigen presenting cells, adhesion molecules, and inflammatory cytokines. While most cases of LP are thought to be idiopathic, some are linked to medication use or hepatitis $C$ and $B$ virus infection [7].

The prevalence of liver disease in lichen planus varies widely in the literature, ranging from $0.1 \%$ to $35 \%$. Studies showed that Hepatitis $\mathrm{C}$ virus plays an etiopathogenetic role in most cases of liver diseases documented in patients with lichen planus [8]. Chronic hepatitis $C$ is associated with a variety of dermatological conditions including cytoglobulinemia with leucocytoclastic vasulitis, porphyria cutanea tarda and LP. Current studies have shown that Hepatitis C virus is the main cause for liver disease seen in some patients with lichen planus especially erosive type of LP [9].

The SGOT and SGPT levels are normally present in the serum in low concentration. The level of these enzymes is usually raised in hepatic disorders like hepatitis and primary biliary cirrhosis. These enzymes are released into the blood in greater amounts when there is damage to the liver cell membrane resulting in increased permeability [5]. Several studies found that the prevalence of liver diseases with LP varies from $4 \%$ to $13.5 \%$ in series based on the determinants like SGOT and SGPT levels [10-12].

Hence in the present study we investigated the presence of liver disease in 30 OLP patients who visited the outpatient clinic in Department of Oral Medicine. SGOT and SGPT levels were estimated in both the study and control group and compared between them.

In the present study SGOT levels were significantly increased in OLP than in healthy controls. The levels of SGPT were also elevated in OLP compared to healthy controls but were not statistically significant. Similar results were observed by Cribier et al. [13]; Bagan et al. [14]; Ali and Suresh [9]; Cribier et al. [13] has observed elevated levels but were not statistically significant between both the groups.

On the other hand, Kabir et al. [15]; Ingafou et al. [16]; BokorBratic [17] found that all the OLP patients had normal liver function and the mean SGOT and SGPT levels are within normal limits in both the groups. These study results were dissimilar to the results our study. All these studies concluded that the association between HCV and OLP is inconsistent and possibly influenced by the geographic distribution of HCV disease and / or genetically based factors [15-17].

Several studies support the possible link between HCV and LP $[18,19]$. The prevalence of HCV infection in patients with LP varies considerably from one geographic area to another ranging from $4 \%$ in northern France to $62 \%$ in Japan [20]. It has been suggested that discrepancies observed between studies from different countries could reflect the varying geographical distribution of HCV infection between countries, or a genetic predisposition in relation to immune responsiveness [9].
Although there is slight elevation of SGPT level in LP patients compared with control group in our study but there is no statistically significant difference observed. In addition SGOT level in LP patents were statistically elevated compared to control. Elevated SGOT levels can be seen in various non hepatic causes like skeletal muscle disorders, acute myocardial infarction, congestive heart failure, pericardititis, and generalized infection [5]. Hence the raised SGOT levels in our study are not very significant \& can be attributed to these causes.

Even though an increased level of SGOT enzymes in the absence of elevated SGPT levels were observed in our study but this does not signify any liver disease. It is not always that liver cell necrosis is required for the release of the SGOT and SGPT and in addition there is a poor correlation between the degree of liver cell damage and the level of the SGOT and SGPT. Thus, the absolute elevation of these enzymes is of no prognostic significance in acute hepatocellular disorders [6].

Erosive form was the most common clinical type, followed by reticular and bullous type of OLP was observed in our study. The mean SGOT and SGPT levels were higher in patients with erosive oral lichen planus compared to those with non erosive lesions. These results were similar to Ali and Suresh [9]; Bagan et al. [14]. Ali and Suresh [9] has concluded that the presence of greater liver alterations, there is correspondingly greater tendency toward development of more aggressive oral lesions [9].

The geographic differences in the prevalence of LP associated with HCV infection might simply reflect overall differences in HCV epidemiology against a background of similar prevalence of LP from country to country. Studies done in British population found that liver function tests were within normal in lichen planus patients. While LP was associated with HCV infection and liver disease in some southern European and other patients, such a co occurrence was not detected in British patients. The apparent lack of an association between HCV infection and chronic liver disease with LP may be due to low prevalence of HCV infection in UK low (0.088- 0.55\%) compared with countries such as Italy $(0.7-1.3 \%)[16]$. Hence the association of HCV infection with chronic liver disease and in turn the association with LP is dependent on geographic distribution.

To conclude our study showed no significant association of chronic liver disease in patients with oral lichen planus. It can be understood that since the prevalence of hepatitis $C$ is very low in this part of India that is less than $(0.87 \%)$ compared to that of worlds prevalence of $3 \%$, hence there was no significant elevation of SGPT levels in our study. Further larger samples with PCR based analysis for HCV has to be done to find the correlation between oral lichen planus and liver disease.

\section{References}

1. Rajendran R, Sivapathasundharam B (2006) Shafer's text book of oral pathology, 5th edn Elsevier publisher, pp. 1103-1107.

2. Strauss RA, Fattore L, Soltani K (1989) The association of mucocutaneous lichen planus and chronic liver disease. Oral Surg Oral Med Oral pathol 68 406-410.

3. Scully C, Beyli M, Ferreiro MC, Ficarra G, Gill Y, et al. (1998) Update on ora Lichen Planus: Etiopathogenesis and Management. Crit Rev Oral Biol Med 9: 86-122.

4. Carrozo $M(2008)$ Oral diseases associated with hepatitis $C$ virus infection. Part 2: Lichen planus and other diseases. Oral diseases 14: 217-228.

5. Technical Bulletin Alanine Aminotransferase (ALT) and Aspartate Aminotransferase [Online] (2007) [cited 2009 September 24]; Available from: URL: http://www.cholestech.com/docs/test info/tbALTAST. 
Citation: Nellithady GS, Anila K, Kumar KK, Kaveri H (2010) Lack of Association of Chronic Liver Disease in Patients with Oral Lichen Lanus. J Carcinogene Mutagene 1:113. doi:10.4172/2157-2518.1000113

Page 4 of 4

6. Fauci AS, Kasper DL, Longo DL, Loscalzo J, Braunwald E, et al. (2008) Harrisons'principles of internal medicine. Vol 2. 17th edn Newyork Mc Graw Hil publishers pp. 1918-1925.

7. Harman M, Akdeniz S, Dursun M, Akpolat N, Atmaca S (2004) Lichen planus and hepatitis $C$ virus infection: an epidemiologic study. Int J Clin Pract 58: 11181119 .

8. Mignogna MD, Lo Muzio L, Favia G, Mignogna RE, Carbone R, et al. (1998) Oral lichen planus and HCV infection: a clinical evaluation of 263 cases. Int $\mathrm{J}$ Dermatol 37: 575-578.

9. Ali AA, Suresh CS (2007) Oral lichen planus in relation to transaminase levels and hepatitis $C$ virus. J Oral Pathol Med 36: 604-608.

10. Rebora A, Rongioletti F, Canepa A (1982) Chronic active hepatitis and lichen planus. Acta Derm Venereol 62: 351-352.

11. Korkij W, Chuang TY, Soltani K (1984) Liver abnormalities in patients with lichen planus. A retrospective case-control study. J Am Acad Dermatol 11: 609-615.

12. Lodi G, Porter SR (1997) Hepatitis C virus infection and lichen planus: a short review. Oral Dis 3: 77-81.

13. Cribier B, Garnier C, Laustriat D, Heid E (1994) Lichen planus and hepatitis C virus infection: An epidemiologic study. J Am Acad Dermatol 31: 1070-1071.
14. Bagán JV, Aguirre JM, del Olmo JA, Milián A, Peñarrocha M, et al. (1994) Oral lichen planus and chronic liver diseases: A clinical and morphometry study of the oral lesions in related to transaminase elevation. Oral Surg Oral Med Oral Pathol 78: 337-342.

15. el-Kabir M, Scully C, Porter S, Porter K, Macnamara E (1993) Liver function tests in UK Patients with Oral lichen planus. Clin Exp Dermatol 18: 12-16.

16. Ingafou M, Porter SR, Scully C, Teo CG (1998) No evidence of HCV infection or liver disease in British patients with oral lichen planus. Int $\mathrm{J}$ Oral Maxillofac Surg 27: 65-66.

17. Bokor-Bratic M (2004) Lack of evidence of hepatic disease in patients with oral lichen planus in Serbia. Oral Dis 10: 283-286.

18. Mokni M, Rybojad M, Puppin D Jr, Catala S, Venezia F, et al. (1991) Lichen planus and hepatitis C virus. J Am Acad Dermatol 24: 792.

19. Gandolfo S, Carbone M, Carrozzo M, Gallo V (1994) Oral lichen planus and hepatitis $\mathrm{C}(\mathrm{HCV})$ infection: Is there is a relationship? A report of 10 cases. Oral Pathol Med 23: 119-122.

20. Daramola OO, George AO, Ogunbiyi AO (2002) Hepatitis C virus and lichen planus in Nigerians: any relationship? Int J Dermatol 41: 217-219. 